\title{
ANALYSIS OF PRINCIPLE DIMENSION AND SHAPE OF \\ PURSE SEINERS IN AMBON ISLAND
}

\author{
Helly S. Lainsamputty \\ e-mail: hellylines@gmail.com \\ Program Studi Teknik Perkapalan, Fakultas Teknik Universitas Pattimura - Ambon
}

\begin{abstract}
Purse seiners as a ship's main small pelagic fish Catcher is increasingly growing in number and size. In the last 5 years has been an increase in purse seine boats in Maluku by $20 \%$ and $15 \%$ of the overall operating in waters around the island of Ambon. Purse seiners tend to be made traditionally based on experience and not in accordance with the criteria of size comparison of a fish boat. It is very technical and operational feasibility of affect in this speed, stability and longitudinal strength. This research aims to calculate speed, tonnage (GT), the size of the principal as well as set the geometric shapes of purse seiners on the island of Ambon. The methods used in this research is a survey method by gathering primary and secondary data by making observations and measurements directly against the 32 purse seiners in Ambon island. Analysis and discussion is done through estimation the ship's speed by using the formula of Nomura, estimated tonnage (GT) using the Standard Fish Vessel Regulations by the Director-General of Fisheries Catch of Indonesia in 2004, the determination of the optimal size of the principal ship in the empirical formula by numerical Traung and geometric forms of purse seiner. Estimation against speed (V) and the tonnage (GT) shows that the speed average $($ Vaverage $)=7.1$ knots and tonnage average $($ GTaverage $)=22.4$ tons. The calculation of the size of the principal ship by using empirical methods-numerical based on Traung equation with input of Vaverage and GTaverage indicates that the principal dimension is as follows: $\mathrm{L}_{\mathrm{BP}}=15.8$ meters; $\mathrm{B}=4.8$ meters; $\mathrm{D}=2.2$ meters and $\mathrm{d}=1.9$ meters and form coefficient as follows: $\mathrm{C}_{\mathrm{B}}=0,6 \quad ; \mathrm{C}_{\mathrm{W}}=0,7 \quad ; \mathrm{C}_{\mathrm{M}}=0,97 \quad ; \mathrm{C}_{\mathrm{P}}=0,62$
\end{abstract}

Keyword : purse seiner, speed, tonnage(GT), principle dimension

\section{PENDAHULUAN}

Kapal-kapal purse seine di Pulau Ambon masih dibuat secara tradisional berdasarkan pengalaman pembuatnya.Di dalam pembuatannya, para pemilik kapal(owner requirement) cenderung memilih kapal purse seine dalam tonase (GT) besar dengan kecepatan yang maximal. Pemilihan ukuran pokoknya juga sangat beragam dan tidak proporsional terutama perbandingan panjang dan lebar (L/B); panjang dan tinggi(L/D) dan lebar dan tinggi (B/D).L/B mempengaruhi kecepatan dan tahanan kapal; L/D mempengaruhi kekuatan memanjang kapal dan $\mathrm{B} / \mathrm{D}$ mempengaruhi stabilitas kapal.L/D semakin kecil akan menyebabkan tahanan kapal membesar (kecepatan mengecil), L/B semakin besar akan mengurangi kekuatan memanjang dan $\mathrm{B} / \mathrm{D}$ semakin besar akan memperburuk propulsive ability.'

Dengan menerapkan kriteria perbandingan ukuran pokok kapal ikan (Fyson 1985, FAO 1996, Ayodhyoa 1972), ternyata dari 32 sampel kapal purse seine di Pulau Ambon ada 93,75\% tidak memenuhi perbandingan $\mathrm{L} / \mathrm{B} ; 50 \%$ tidak memenuhi perbandingan $\mathrm{B} / \mathrm{D}$ dan $81,25 \%$ tidak memenuhi perbandingan L/D. Untuk itu, perlu dilakukan kajian terhadap penentuan ukuran,tonase dan bentuk yang proporsional sebagai alternatif pengembangan terhadap desain kapal purse seine yang lebih efisien di Pulau Ambon.
Kapal purse seine digunakan khusus untuk menangkap ikan pelagis dengan menggunakan jaring pukat cincin(purse seine) yang berbentuk empat persegi dengan banyak cincin yang menggantung pada bagian dasarnya.Pengoperasiannya adalah dengan cara melingkarkan jaring untuk mengurung gerombolan ikan dan setelah ikan terkurung, bagaian dasar jaring ditutup dengan cara menarik tali purse.

\section{KAJIAN TEORI DAN METODE}

Penelitian ini dilakukan di Fakultas Teknik Universitas Pattimura. Sumber data yang digunakan adalah data-data ukuran kapal purse seine yang telah dibuat dan masih beroperasi dalam penangkapan ikan. Sampel yang diambil adalah 32 kapal purse seine yang berpangkalan di desa Waai, Latuhalat dan Hitu Pulau Ambon.

Perhitungan diawali dengan mengevaluasi perbandingan ukuran pokok kapal berdasarkan kriteria perbandingan ukuran pokok kapal ikan (Fyson 1985, FAO 1996, Ayodhyoa 1972 dan BKI 2004).Kemudian dilanjutkan dengan estimasi kecepatan (V) dan tonase (GT) dari kapal-kapal purse seine tersebut. Setelah itu dilakukan estimasi ukuran pokok dan bentuk lambung kapal.

\section{Evaluasi perbandingan ukuran pokok}

Evaluasi terhadap perbandingan ukuran pokok dari kapal-kapal purse seine yang ada di Pulau 
Ambon menggunakan kriteria perbandingan ukuran pokok kapal ikan (Fyson 1985; FAO 1996; Ayodhyoa 1972), di mana nilai perbandingannya adalah sebagai berikut: $\mathrm{L} / \mathrm{B}=3,10-4,30 ; \mathrm{B} / \mathrm{D}=-$ $2,10-5,00$ dan $\mathrm{L} / \mathrm{D}=9,50-11,00$.

\section{Estimasi kecepatan kapal}

Ukuran utama kapal ikan (L, B, D), koefisien bentuk, displasemen,bentuk lambung kapal di bawah garis sarat, trim, pemilihan mesin merupakan komponen-komponen yang mempengaruhi kecepatan kapal ikan. Kecepatan kapal ikan dinyatakan dengan satuan knot $(1$ knot $=1,852$ $\mathrm{km} / \mathrm{jam}$ ).Kecepatan kapal ikan dapat dihitung dengan rumus Nomura (1975) sebagai berikut:

$$
\mathrm{V}=1,811 \sqrt{L}
$$

di mana :

$$
\begin{aligned}
& \mathrm{V}=\text { kecepatan kapal }(\mathrm{knot}) \\
& \mathrm{L}=\text { panjang kapal pada garis air, } \mathrm{L}_{\mathrm{wL}}(\text { meter) }
\end{aligned}
$$

\section{Estimasi tonase(GT) kapal}

Gross tonnage (GT) kapal purse seine dapat ditentukan dengan mengggunakan Peraturan Kapal Ikan Standard oleh Dirjen Perikanan Tangkap Tahun 2004 yaitu :

di mana :

$$
\mathrm{GT}=\frac{\text { L.E.L.C }}{2,8}
$$

$$
\begin{aligned}
\mathrm{G}_{\mathrm{T}} & =\text { gross tonnage }(\text { ton }) \\
\mathrm{L} & =\text { panjang kapal keseluruhan, } \mathrm{L}_{\mathrm{OA}}(\mathrm{m}) \\
\mathrm{B} & =\text { lebar kapal }(\mathrm{m}) \\
\mathrm{D} & =\text { tinggi geladak }(\mathrm{m})
\end{aligned}
$$

\section{Estimasi ukuran pokok kapal}

Ukuran pokok kapal meliputi panjang antar garis tegak $\left(\mathrm{L}_{\mathrm{BP}}\right)$, lebar kapal (B), tinggi geladak (D) dan tinggi sarat (d). Ukuran pokok kapal dapat ditentukan berdasarkan pendekatan daya angkut (GT) dan kecepatan (V).Penentuan ukuran pokok kapal dapat dilakukan secara numerik - empiris dengan menggunakan rumus pendekatan berdasarkan Traung (1960), yaitu :

- $\mathrm{L}_{\mathrm{BP}}=(5,30-5,60) \times \sqrt[3]{G}$

- $\mathrm{B}=\left(0,11 \times \mathrm{L}_{\mathrm{BP}}\right)+(2,9$ hingga $3,1 \mathrm{~m})$

- $\mathrm{D}=\left(0,068 \times \mathrm{L}_{\mathrm{BP}}\right)+(0,9$ hingga $1,1 \mathrm{~m})$

- $\mathrm{d}=0,85 \times \mathrm{D}$

- Koreksi angka Froude, $\mathrm{F}_{\mathrm{r}}=\frac{V}{\sqrt{g}}$, dengan batasan $0,30 \leq \mathrm{F}_{\mathrm{r}} \leq 0,35$.

di mana $: v=$ kecepatan kapal $(\mathrm{m} / \mathrm{det})$ $g=$ percepatan gravitasi $=9,8 \mathrm{~m} / \mathrm{det}^{2}$ $L_{b p}=$ panjang antar garis tegak $(\mathrm{m})$

- Perbandingan ukuran pokok kapal menurut Traung (1960) adalah :

$\mathrm{L} / \mathrm{B}=3,09-4,69$;

$\mathrm{L} / \mathrm{D}=5,69-10,39$
B: $\mathrm{D}-1,77-2,32$

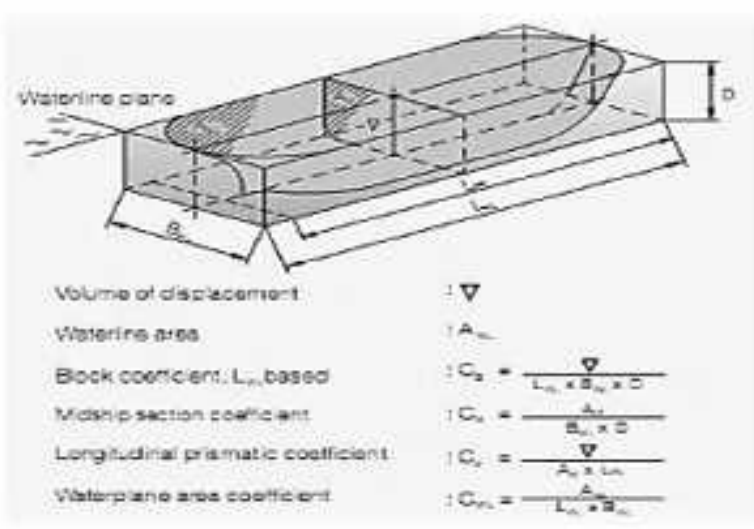

Gambar.1. Ukuran pokok dan kocfisien bentuk kapal

\section{Estimasi koefisien bentuk lambung}

Koefisien bentuk lambung kapal dapat ditentukan dengan persamaan menurut Amos Ayres (1978), Munro Smith (1975), Van Lameren (1978) dan Nomura (1975) sebagai berikut :

\section{- Koefisien Blok}

Koefisien blok ini menggambarkan bentuk badan kapal. Koefisen blok dapat dihitung dengan rumus berikut :

di mana:

$$
\mathrm{C}_{\mathrm{B}}=1.08-\frac{\mathrm{u}, 5 \mathrm{~V}}{\sqrt{\mathrm{L}}}
$$

$$
\begin{aligned}
& \mathrm{V}=\text { kecepatan kapal }(\mathrm{knot}) \\
& \mathrm{L}=\text { panjang kapal antar garis tegak } \mathrm{L}_{\mathrm{BP}}(\mathrm{feet})
\end{aligned}
$$

Koefisien blok kapal in sangat menentukan besarnya tahanan kapal. Semakin besar koefisien blok kapal maka semakin besar tahanan kapal, dan begitu juga sebaliknya, namun dengan koefisien blok yang kecil maka kecepatan kapal akan meninggi.

Standard teknis koefisien blok kapal purse seine: $\mathrm{C}_{\mathrm{B}}=0,40-0,68$.

\section{- Koefisien Garis Air}

Koefisien garis air ini menunjukkan bentuk garis air kapal (stream line). Koefisien garis air dapat ditentukan sebagai berikut :

$$
\mathrm{C}_{\mathrm{W}}=\mathrm{C}_{\mathrm{B}}+0,1
$$

Standard teknis koefisien garis air kapal purse seine $: \mathrm{C}_{\mathrm{W}}=0,76-0,92$.

\section{- Koefisien GadingTengah}

Koefisien gading tengah menggambarkan bentuk badan kapal terutama di bagian tengah kapal. Koefisien gading tengah kapal dapat dihitung dengan rumus berikut :

$$
\mathrm{C}_{\mathrm{M}}=0,9+0,1 \mathrm{C}_{\mathrm{B}}
$$

Standard koefisien gading tengah kapal purse seine :

$\mathrm{C}_{\mathrm{M}}=0,91-0,95$. 


\section{- Koefisien Prismatk}

Koefisien prismatik menggambarkan bentuk memanjang lambung kapal.Koefisien prismatik dapat ditentukan sebagai berikut :

$$
\mathrm{C}_{\mathrm{P}}=\mathrm{C} / \mathrm{C}
$$

Standard koefisien prismatik kapal purse seine :

$\mathrm{C}_{\mathrm{P}}=0,55-0,78$.

\section{HASIL DAN PEMBAHASAN}

\section{- Koreksi Perbandingan Ukuran Pokok}

Berikut ini dapat dilihat koreksi terhadap perbandingan ukuran pokok dari kapal-kapal purse seine yang ada di Pulau Ambon dengan menggunakan kriteria kapal ikan (Fyson 1985;

FAO 1996; Ayodhyoa 1972), sebagai berikut:

Tabel.1. Koreksi perbandingan ukuran pokok kapal

\begin{tabular}{|c|c|c|c|c|}
\hline No. & Nama Kapal & $\begin{array}{c}\mathrm{L} / \mathrm{B} \\
(\mathbf{3 , 1 0}- \\
\mathbf{4 , 3 0})\end{array}$ & $\begin{array}{c}\text { B/D } \\
(2,10- \\
5,00)\end{array}$ & $\begin{array}{c}\text { L/D } \\
(9,50- \\
11,00)\end{array}$ \\
\hline 1. & Ade Yeni & 5,3 & 2,0 & 10 \\
\hline 2. & Barista & 4,8 & 2,7 & 12,9 \\
\hline 3. & Berkat & 5,8 & 2,3 & 13,5 \\
\hline 4. & Fajar 01 & 5,8 & 2,3 & 13,5 \\
\hline 5. & Fiber 05 & 4,8 & 2,8 & 11,1 \\
\hline 6. & Fina & 5,5 & 1,6 & 9,1 \\
\hline 7. & GPI 05 & 4,1 & 2,0 & 8,3 \\
\hline 8. & KM 007 & 5,3 & 2,1 & 11,4 \\
\hline 9. & MIO 02 & 5,0 & 2,0 & 10,0 \\
\hline 10. & Risna 01 & 5,5 & 1,7 & 9,2 \\
\hline 11. & Risna 07 & 4,9 & 2,1 & 10,5 \\
\hline 12. & Samsan 01 & 6,0 & 2,5 & 15,0 \\
\hline 13. & Chrisly & 5,6 & 1,7 & 9,7 \\
\hline 14. & Dwifin & 6,3 & 1,7 & 10,8 \\
\hline 15. & Manuwai 01 & 5,2 & 2,3 & 11,9 \\
\hline 16. & Manuwai 02 & 5,5 & 2,4 & 13,1 \\
\hline 17. & Manu Indah & 3,7 & 2,3 & 8,6 \\
\hline 18. & Man Indah & 5,3 & 2,3 & 12,0 \\
\hline 19. & Kube 14 & 4,3 & 2,5 & 10,6 \\
\hline 20. & Dewaruci 02 & 4,9 & 2,4 & 11,7 \\
\hline 21. & Dewaruci 03 & 5,6 & 1,6 & 9,0 \\
\hline 22. & Fajar Anggada & 6,0 & 2,2 & 12,9 \\
\hline 23. & Fajar Laut & 5,9 & 1,5 & 8,9 \\
\hline 24. & Garuda 02 & 4,8 & 2,7 & 12,8 \\
\hline 25. & Haulawa & 5,6 & 1,7 & 12,8 \\
\hline 26. & Hidup Baru & 6,0 & 1,4 & 8,7 \\
\hline 27. & Manusela & 5,7 & 1,5 & 8,5 \\
\hline 28. & Matrik & 5,0 & 2,7 & 13,7 \\
\hline 29. & Timinusa & 6,6 & 1,6 & 10,5 \\
\hline 30. & Uluputih 01 & 7,1 & 1,8 & 13,0 \\
\hline 31. & Waindua & 5,5 & 1,4 & 8,0 \\
\hline 32. & Yaba Hitu & 5,7 & 1,4 & 8,0 \\
\hline
\end{tabular}

Berdasarkan koreksi di atas terlihat bahwa ada 30 kapal $(93,75 \%)$ tidak memenuhi nilai L/B ; 16 kapal $(50,00 \%)$ tidak memenuhi nilai B/D dan 26 kapal $(81,25 \%)$ tidak memenuhi nilai L/D.

\section{-Estimasi Kecepatan Rata-Rata dari Kapal- Kapal Purse Seine}

Estimasi kecepatan rata-rata kapal purse dapat dilakukan dengan menggunakan rumus Nomura (1975) adalah sebagai berikut:

Tabel.2. Estimasi kecepatan kapal-kapal purse seine.

\begin{tabular}{|c|l|c|c|}
\hline No. & \multicolumn{1}{|l|}{ NAMA KAPAL } & LwL & $\begin{array}{c}\mathrm{V}=1,811 \sqrt{L} \\
(\mathrm{knot})\end{array}$ \\
\hline 1. & ADE YENY & 16,0 & 7,2 \\
\hline 2. & BARISTA & 15,5 & 7,1 \\
\hline 3. & BERKAT & 16,2 & 7,3 \\
\hline 4. & FAJAR 01 & 17,5 & 7,6 \\
\hline 5. & FIBER 05 & 15,5 & 7,1 \\
\hline 6. & FINA & 15,5 & 7,1 \\
\hline 7. & G P I 05 & 12,5 & 6,4 \\
\hline 8. & KM 007 & 16,0 & 7,2 \\
\hline 9. & M I O 02 & 15,0 & 7,0 \\
\hline 10. & RISNA 01 & 16,5 & 7,4 \\
\hline 11. & RISNA 07 & 15,8 & 7,2 \\
\hline 12. & SAM SAN 01 & 18,0 & 7,7 \\
\hline 13. & CHRISLY & 17,5 & 7,6 \\
\hline 14. & DWIFIN & 19,5 & 8,0 \\
\hline 15. & MANUWAI 01 & 21,5 & 8,4 \\
\hline 16. & MANUWAI 02 & 21,0 & 8,3 \\
\hline 17. & MANU INDAH & 18,0 & 7,7 \\
\hline 18. & MANURUSI INDAH & 21,6 & 8,4 \\
\hline 19. & KUBE 14 & 18,0 & 7,7 \\
\hline 20. & DEWARUCI 02 & 17,5 & 7,6 \\
\hline 21. & DEWARUCI 03 & 18,0 & 7,7 \\
\hline 22. & FAJAR ANGGADA & 15,5 & 7,1 \\
\hline 23. & FAJAR LAUT & 19,5 & 8,0 \\
\hline 24. & GARUDA 02 & 15,4 & 7,1 \\
\hline 25. & HAULAWA & 19,5 & 8,0 \\
\hline 26. & HIDUP BARU & 19,2 & 7,9 \\
\hline 27. & MANUSELA & 17,0 & 7,5 \\
\hline 28. & MATRIK & 16,5 & 7,4 \\
\hline 29. & TIMINUSA & 21,0 & 8,3 \\
\hline 30. & ULUPUTIH 01 & 15,6 & 7,1 \\
\hline 31. & WAINDUA & 17,6 & 7,6 \\
\hline 32. & YABA HITU & 20,0 & 8,1 \\
\hline & & & 7,1 \\
\hline & & & \\
\hline & & & \\
\hline
\end{tabular}

Dari perhitungan kecepatan kapal purse seine diperoleh kecepatan rata-rata $=7,1$ knot.

\section{- Estimasi tonase (GT) kapal}

Estimasi terhadap tonase (GT) kapal-kapal purse seine dengan mengggunakan Peraturan Kapal Ikan Standard oleh Dirjen Perikanan Tangkap Tahun 2004 adalah sebagai berikut: 
Tabel.3. Estimasi tonase (GT) kapal-kapal purse seine.

\begin{tabular}{|c|c|c|}
\hline No. & NAMA KAPAL & $\begin{aligned} \mathrm{GT}=\frac{\text { L.B.E.LE}}{2, \mathrm{G}} \\
\\
\text { (ton) }\end{aligned}$ \\
\hline 1. & ADE YENY & 16 \\
\hline 2. & BARISTA & 14 \\
\hline 3. & BERKAT & 12 \\
\hline 4. & FAJAR 01 & 15 \\
\hline 5. & FIBER 05 & 16 \\
\hline 6. & FINA & 18 \\
\hline 7. & G P I 05 & 13 \\
\hline 8. & KM 007 & 15 \\
\hline 9. & M I O 02 & 16 \\
\hline 10. & RISNA 01 & 17 \\
\hline 11. & RISNA 07 & 19 \\
\hline 12. & SAM SAN 01 & 15 \\
\hline 13. & CHRISLY & 25 \\
\hline 14. & DWIFIN & 23 \\
\hline 15. & MANUWAI 01 & 36 \\
\hline 16. & MANUWAI 02 & 29 \\
\hline 17. & MANU INDAH & 47 \\
\hline 18. & MANURUSI INDAH & 34 \\
\hline 19. & KUBE 14 & 23 \\
\hline 20. & DEWARUCI 02 & 21 \\
\hline 21. & DEWARUCI 03 & 26 \\
\hline 22. & FAJAR ANGGADA & 11 \\
\hline 23. & FAJAR LAUT & 32 \\
\hline 24. & GARUDA 02 & 15 \\
\hline 25. & HAULAWA & 30 \\
\hline 26. & HIDUP BARU & 31 \\
\hline 27. & MANUSELA & 23 \\
\hline 28. & MATRIK & 14 \\
\hline 29. & TIMINUSA & 32 \\
\hline 30. & ULUPUTIH 01 & 10 \\
\hline 31. & WAINDUA & 29 \\
\hline 32. & YABA HITU & 40 \\
\hline \multicolumn{2}{|r|}{$\mathrm{GT}_{\text {rata-rata }}$} & 22,4 \\
\hline
\end{tabular}

Dari hasil evaluasi GT kapal-kapal purse seine diperoleh $\mathrm{GT}_{\text {rata-rata }}=22,4$ ton.

\section{- Penentuan Ukuran Pokok Optimal Kapal}

Ukuran utama kapal purse seine ini dapat ditentukan dengan menggunakan pendekatan $\mathrm{GT}_{\text {rata- }}$ rata dan $\mathrm{V}_{\text {rata-rata }}$ dari $32 \mathrm{kapal}$ purse seine yang sedang beroperasi sebagai data pembanding (data input), yaitu :

- $\mathrm{V}_{\text {rata-rata }}=7,1 \mathrm{knot}=7,1 \times 0,5144 \mathrm{~m} / \mathrm{det}=$ $3,6522 \mathrm{~m} / \mathrm{det}$

- $\mathrm{GT}_{\text {rata-rata }}=22,4$ ton

Penentuan ukuran pokok kapal dapat dilakukan secara numerik - empiris dengan menggunakan rumus pendekatan berdasarkan Traung (1960),yaitu :

- $\quad \mathrm{L}_{\mathrm{BP}}=$ panjang antar garis tegak $=(5,30-$ $5,60 \times \sqrt[3]{G} \ldots . .(\mathrm{m})$

- $\mathrm{B}=$ lebar kapal $=\left(0,11 \times \mathrm{L}_{\mathrm{BP}}\right)+(2,9$ hingga 3,1$) \ldots . .(\mathrm{m})$

- $\mathrm{D}=$ tinggi geladak $=\left(0,068 \times \mathrm{L}_{\mathrm{BP}}\right)+(0,9$ hingga 1,1$) \ldots . .(\mathrm{m})$

- $\mathrm{d}=$ tinggi sarat $=0,85 \times \mathrm{D} \ldots . .(\mathrm{m})$
- Koreksi angka Froude, $\mathrm{F}_{\mathrm{r}}=\frac{V}{\sqrt{g \times L}}$, dengan batasan $0,30 \leq \mathrm{F}_{\mathrm{r}} \leq 0,35$. di mana :

$$
\begin{aligned}
v & =\text { kecepatan kapal }(\mathrm{m} / \mathrm{det}) \\
g & =\text { percepatan gravitasi } \\
\mathrm{L}_{\mathrm{bp}} & =\text { panjang antar garis tegak }(\mathrm{m})
\end{aligned}
$$

- Perbandingan ukuran pokok kapal adalah : $\mathrm{L} / \mathrm{B}=3,09-4,69 ; \mathrm{L} / \mathrm{D}=5,69-10,39$; $\mathrm{B} / \mathrm{D}=1,77-2,32$

Berdasarkan penetapan di atas maka dilakukan perhitungan terhadap $\mathrm{L}_{\mathrm{BP}}, \mathrm{B}, \mathrm{D}$, dan $\mathrm{d}$, maka diperoleh hasilnya sebagai berikut:

Tabel.4. Penentuan ukuran pokok kapal purse seine.

\begin{tabular}{|c|c|c|c|}
\hline $\begin{array}{c}\text { Ukuran } \\
\text { Pokok }\end{array}$ & Kisaran & $\begin{array}{c}\text { Ditetapkan } \\
(\mathrm{m})\end{array}$ & $\begin{array}{c}\text { Ditentukan } \\
(\mathrm{m})\end{array}$ \\
\hline $\mathrm{L}_{\mathrm{BP}}$ & $(5,30-5,60) \times \sqrt[n]{G}$ & $5,60 \times \sqrt[3]{\mathrm{G}}$ & 15,8 \\
$\mathrm{~B}$ & $\left(0,11 \times \mathrm{L}_{\mathrm{BP}}\right)+(2,9-3,1)$ & $\left(0,11 \times \mathrm{L}_{\mathrm{BP}}\right)+3,1$ & 4,8 \\
$\mathrm{D}$ & $\left(0,068 \times \mathrm{L}_{\mathrm{BP}}\right)+(0,9-1,1)$ & $\left(0,068 \times \mathrm{L}_{\mathrm{BP}}\right)+1,1$ & 2,2 \\
$\mathrm{~d}$ & & $0,85 \times \mathrm{D}$ & 1,9 \\
\hline
\end{tabular}

Koreksi angka Froude berdasarkan ukuran pokok kapal ,maka diperoleh :

$$
\begin{aligned}
\mathrm{F}_{\mathrm{r}} & =\frac{V}{\sqrt{y \times L}} \\
& =\frac{3,6}{\sqrt{9,8 \times 1,4}} \\
& =\frac{3,6}{1,4} \\
\mathrm{~F}_{\mathrm{r}} & =0,30
\end{aligned}
$$

Perbandingan ukuran pokok kapal adalah sebagai berikut :

$$
\begin{aligned}
& \mathrm{L} / \mathrm{B}=15,8 / 4,8=3,29 \\
& \mathrm{~L} / \mathrm{D}=15,8 / 2,2=7,18 \\
& \mathrm{~B} / \mathrm{D}=4,8 / 2,2=2,18
\end{aligned}
$$

Berdasarkan koreksi angka Froude dan perbandingan ukuran pokok kapal menurut Traung (1960) ternyata ukuran pokok kapal cukup layak karena berada pada kisaran seperti terlihat pada tabel berikut ini :

Tabel.5. Koreksi ukuran pokok kapal hasil perhitungan

\begin{tabular}{|c|c|c|}
\hline Koreksi & Nilai & Kisaran \\
\hline L/B & 3,29 & $3,09-4,69$ \\
L/D & 7.18 & $5,69-10,39$ \\
B/D & 2.18 & $1,77-2,32$ \\
Fr & 0,30 & $0,30-0,35$ \\
\hline
\end{tabular}

\section{- Koefisien bentuk lambung}

Berdasarkan ukuran pokok yang telah ditetapkan di atas maka dapat digambarkan bentuk geonmetris kapal purse seine menurut penentuan koefisien bentuknya, sebagai berikut:

- Koefisien Blok : $\mathrm{C}_{\mathrm{B}}=1.08-\frac{0,5 \mathrm{~V}}{\sqrt{\mathrm{L}}}$ di mana :

$$
\begin{aligned}
\mathrm{v} & =\text { kecepatan kapal }(\mathrm{knot})=7,1 \mathrm{knot} \\
\mathrm{L} & =\text { panjang antar garis tegak, } \mathrm{L}_{\mathrm{BP}}(\text { feet }) \\
& =52,14 \text { feet }
\end{aligned}
$$




$$
\text { Maka : } \begin{aligned}
\mathrm{C}_{\mathrm{B}} & =1,08-\frac{0,5 \times 7,1}{\sqrt{5,1}}=1,08-\frac{3,5}{7,2} \\
& =1,08-0,49 \\
\mathrm{C}_{\mathrm{B}} & =0,6
\end{aligned}
$$

- Koefisien garis air : $\mathrm{C}_{\mathrm{W}}=\mathrm{C}_{\mathrm{B}}+0,1$

$$
=0,6+0,1
$$$$
\mathrm{C}_{\mathrm{W}}=0,7
$$

- Koefisien midship : $\mathrm{C}_{M}=\left(0,08 \times \mathrm{C}_{\mathrm{B}}\right)+0,93$

$$
\begin{aligned}
& =(0,08 \times 0,6)+0,93 \\
C_{M} & =0,95
\end{aligned}
$$

- Koefisien prismatik: $\mathrm{C}_{\mathrm{P}}=\mathrm{C}_{\mathrm{B}} / \mathrm{C}_{\mathrm{M}}=0,6 / 0,97=0,62$

\section{KESIMPULAN}

Berdasarkan evaluasi dan perhitungan terhadap 32 kapal purse seine di Pulau Ambon maka diperoleh:

- Ukuran pokok kapal maximal adalah sebagai berikut:

Panjang antar garis tegak $\left(\mathrm{L}_{\mathrm{BP}}\right)=15,8 \mathrm{~m}$

Lebar kapal $(B)=4,8 \mathrm{~m}$

Tinggi geladak $(\mathrm{D})=2,2 \mathrm{~m}$

Tinggi sarat air $(\mathrm{d})=1,9 \mathrm{~m}$

- Kecepatan kapal $(\mathrm{V})=7,1 \mathrm{knot}$

- Tonase $(\mathrm{GT})=22,4$ ton

- Koefisien bentuk kapal, antara lain:

$$
\mathrm{C}_{\mathrm{B}}=0,6 ; \mathrm{C}_{\mathrm{W}}=0,7 ; \mathrm{C}_{\mathrm{M}}=0,97 ; \mathrm{C}_{\mathrm{P}}=0 \text {, }
$$

\section{DAFTAR PUSTAKA}

Ayodhyoa,1972.Fishing Boat Correspondence Course Center.Fakultas Perikanan Institut Pertanian,Bogor

Ayodhyoa,1985. Suatu Pengenalan Fishing Gear . Fakultas Perikanan Institut Pertanian, Bogor

Departemen Kelautan dan Perikanan RI, 2009. Undang Undang Nomor 31 Tahun 2009 Tentang Jenis Kapal Perikanan, Jakarta

Dinas Kelautan dan Perikanan Maluku, 2017. Laporan Statistik Tahunan Perikanan Provinsi Maluku, Ambon
FAO .2013.Fishing Gear Types: Purse Seines.FAO of the United Nations.Fisheries and Aquaculture

Department.www.fao.or/fishery/geartype

Fyson, J, 1985. Design of Small FishingVessels.FAO United Nations. Fishing New Book Ltd, England.173p

Koesdi, Z, 1981. Perencanaan dan Pengelolaan Kapal Ikan

Lewis ,Edward,V,1988. Principle of Naval Architecture Second Edition, The Society of Naval Architecture and Marines Engineers, New JerseyLackenby,H and Milton,D, 1965. DTMB Standard Series 60. A New Presentation of The Resistance Data for Block Coefficient, LCB, Breadth-Draught Ratio and LengthBreadth Ratio Variations. British Ship Research Association (BSRA), London.75p

Nomura,M dan T.Yamazaki. 1977. Fishing Technic(1). Japan InternationalCorporation Agency, Tokyo.205p

Rawson,KJ and EC.Tupper,1994.Basic Ship Theory.Vol.1.Hydrostatic and Strength.4th edition.Longman Group Ltd.England.375p

Traung, JO, 1960. Fishing Boats of The World 2. Fishing News Books Ltd, Roma.830p

Tamaela MJ,1988. Rancang Kapal I. Fakultas Teknik Perkapalan. Univ.Pattimura.123p

Tsudani T.1983.Illustration of Japanese Fishing Boats,Seizando-ShotenPublishing Co.Ltd,Tokyo.190p

Yahya, 2001. Perikanan Tangkap Indonesia . Fakultas Perikanan dan Ilmu Kelautan,IPB, Bogor

Watson,DGM, 2002. Practical Ship Design. Elseiver Science Ltd, Oxford.558p 